\title{
Hair loss perception and symptoms of depression in female outpatients attending a general dermatology clinic $^{*}$
}

\section{Percepção de queda de cabelos e sintomas depressivos em pacientes do sexo feminino em ambulatório de dermatologia geral}

\author{
Juliano Vilaverde Schmitt ${ }^{1}$ \\ Fernanda Homem de Mello de Souza ${ }^{2}$ \\ Fernanda Regina Lemos Bebber ${ }^{2}$
}

\author{
Camila Ferrari Ribeiro ${ }^{2}$ \\ Elisa Beatriz Dalledone Siqueira ${ }^{2}$
}

\begin{abstract}
BACKGROUND: Hair loss is a common complaint among women and may be associated with psychological disturbances. OBJECTIVEs: This study investigated dermatology patients with respect to the prevalence of complaints of hair loss and the association between these complaints and symptoms of depression.

METHODS: A cross-sectional study was conducted with female outpatients over 20 years of age with no hair-related disorders. Patients were asked about hair loss and were evaluated with respect to symptoms of depression. The following variables were also analyzed: age, dermatological diagnosis, comorbidities, medications, family history of alopecia, hair length, the number of hairs extracted in the hair pull test and the presence of hair thinning or seborrheic dermatitis. Data were compared by bivariate analysis and multiple logistic regressions between groups of women with and without hair loss.

ResulTs: Of the 157 women interviewed, $54 \%$ reported hair loss and 29\% reported at least two key symptoms of depression. The median (IQD) age of the women was 51 (20) years. Complaints of hair loss were associated with the presence of symptoms of depression even following adjustment for the other covariates $(\mathrm{p}=0.02 ; \mathrm{OR}=2.79 ; 95 \% \mathrm{CI}$ : 1.18-6.61). Statistically significant differences were also found between the patients with and without hair loss with respect to: age $(p=0.03)$, family history of alopecia $(p<0.01)$, hair length $(p=0.01)$, number of hairs extracted in the hair pull test $(\mathrm{p}=0.02)$, hair thinning $(\mathrm{p}<0.01)$, seborrheic dermatitis $(\mathrm{p}<0.01)$ and problems with personal relationships $(\mathrm{p}=0.04)$.

Discussion: Hair-related disorders are a common topic of interest in this population. The significant association found between this complaint and symptoms of depression indicates a relationship between the perception of hair loss and the psychological well being of the women evaluated.

ConcLusion: Complaints of hair loss were common and were associated with a greater prevalence of symptoms of depression among adult female outpatients at a public dermatology clinic.

Keywords: Alopecia; Depression; Hair; Women
\end{abstract}

Resumo: Fundamentos: Queda de cabelos é queixa frequente entre mulheres, podendo estar relacionada a comprometimento psicológico.

OBjEtrvos: Investigar a prevalência da queixa de queda capilar em pacientes dermatológicas e sua associação com sintomas depressivos.

MÉTODos: Estudo transversal com pacientes femininas, ambulatoriais, maiores de 20 anos de idade, sem doenças capilares. Foram questionadas quanto à presença de queda de cabelos e avaliadas quanto à presença de sintomas depressivos. Também analisaram-se: idade, diagnóstico dermatológico, comorbidades, medicações, história familiar de alopecia, comprimento capilar, número de fios obtidos à tração e presença de rarefação capilar ou dermatite seborreica. Os dados foram comparados bivariadamente e por regressão logística múltipla entre os grupos com e sem queixa de queda capilar.

RESULTADOS: Das 157 mulheres entrevistadas, $54 \%$ referiam queda capilar e 29\%, ao menos dois sintomas depressivos fundamentais. A idade mediana foi $51+20$ anos. A queixa de queda capilar esteve associada à presença de sintomas depressivos, mesmo quando ajustada pelas demais covariáveis ( $\mathrm{p}=0,02 ; \mathrm{OR}=2,79$ [IC 95\%: 1,18-6,61]). Pacientes com e sem queixa também diferiram, significativamente, quanto à idade $(\mathrm{p}=0,03)$, à história familiar de alopecia $(\mathrm{p}<0,01)$, ao comprimento capilar $(\mathrm{p}=0,01)$, ao número de fios obtidos à tração $(\mathrm{p}=0,02)$, à rarefação capilar $(\mathrm{p}<0,01)$, à dermatite seborreica $(\mathrm{p}<0,01) \mathrm{e}$ a problemas de relacionamento pessoal $(\mathrm{p}=0,04)$.

Discussão: Alterações capilares configuram tema de frequente interesse nessa população. A significativa associação dessa queixa com sintomas depressivos indica relação entre a percepção da saúde capilar e o bem-estar psicológico das mulheres avaliadas. Conclusão: A queixa de queda capilar foi frequente e esteve associada a maior prevalência de sintomas depressivos entre as pacientes adultas de ambulatório dermatológico público.

Palavras-chave: Alopecia; Cabelo; Depressão; Mulheres

Received on 30.03.2011.

Approved by the Advisory Board and accepted for publication on 16.05.2011.

* This study was conducted at the Dermatology Unit, Evangelical Teaching Hospital of Curitiba, Evangelical Medical School of Paraná (HUEC-FEPAR), Curitiba, Paraná, Brazil. Financial Support: None

Conflict of Interests: None

Preceptor, Dermatology Unit, Evangelical Teaching Hospital of Curitiba, Evangelical Medical School of Paraná (HUEC-FEPAR), Curitiba, Paraná, Brazil.

Medical Resident, Dermatology Unit, Evangelical Teaching Hospital of Curitiba, Evangelical Medical School of Paraná (HUEC-FEPAR), Curitiba, Paraná, Brazil. 


\section{INTRODUCTION}

Hair loss is a common complaint in clinical dermatology, with this complaint also being common in the adult population in general when these individuals are specifically asked about it. ${ }^{1}$ On the other hand, it is relatively common in dermatology clinics to find patients with no apparent abnormalities at physical examination who complain of hair loss. This incoherency between the complaint and the findings upon examination may have various origins.

Although women are genetically less susceptible to pronounced alopecia, they are more sensitive to minor capillary abnormalities, possibly due to cultural and behavioral factors. ${ }^{2.5}$

Few studies in the literature have evaluated the profile of hair loss as perceived by the patient from a behavioral point of view. Likewise, the reliability of this impression and its relationship with psychological and clinical aspects has seldom been reported.

A better understanding of this perception and of the possible variables associated with it in women may improve the management of these patients and lead to improvements in clinical dermatology with respect to this disorder.

The present study investigated the prevalence of a perception of hair loss by the patient when specifically questioned on the subject and the variables associated with this perception, particularly the presence of depression symptoms. The study was carried out in adult patients attending a public dermatology clinic.

\section{METHODS}

A prospective, cross-sectional study was conducted between April and August 2010 with female patients of 20 years of age or more, who had presented spontaneously at the outpatient dermatology clinic of a public reference institution in Curitiba, Paraná. Patients who were being treated for capillary disorders were excluded from the study.

After their dermatological consultation, patients were asked the following question: "Do you have any problem with hair loss?" A positive or negative answer to this question was then used to separate the women into a group of complainers and a group of non-complainers, respectively.

The following data were obtained from eligible patients: age, phototype, principal dermatological diagnosis, comorbidities, medication used, family history of hair loss or alopecia, and awareness that the dermatologist treats hair loss. Specific hair features included actual and current hair type (straight, wavy or curly), actual and current hair color (dark or fair), number of shampoos per week, number of colorings per month, length in centimeters of the hair starting from the posterior vertex, and the number of times the hair is combed per day. The patient was examined for the presence of clinical signs of hirsutism, clinical signs of active acne, seborrheic dermatitis of the scalp, and hair thinning at the sagittal midline. Finally, the number of hairs extracted at the hair pull test was recorded.

The hair pull test was performed during the interview by firmly securing a clump of hair between the fingers and gently pulling it from the vertex region of the scalp. No normal limit was established for this test, since the data were evaluated as a continuous variable.

The eligible women were also questioned with respect to the symptoms listed below, based on the International Classification of Diseases $-10^{\text {th }}$ Edition (ICD-10) depression diagnostic criteria. ${ }^{6}$ The first three are considered key symptoms.

Persistent sadness or low mood?

Loss of interest or pleasure in performing routine activities?

Fatigue or low energy?

Feelings of guilt or worthlessness?

Poor concentration or indecisiveness?

Disturbed sleep on a practically daily basis?

The women complaining of hair loss were asked about the duration of the problem, the relationship between the seasons and the severity of the problem and the way in which the problem was perceived, from the following options:

From progressive thinning on the scalp

When combing hair

When taking a bath

From hair on the floor at home

From hair on the pillow

Other people noticed the problem.

The investigator's subjective evaluation regarding the presence of hair thinning at the vertex was validated by standardized photographs of this region of the scalp and by a count of the number of hairs found over an area of $9 \mathrm{~mm}^{2}$ in the first 61 patients. A significant correlation was found between the number of hairs and the investigator's impression of hair thinning (Spearman's rho $=0.34 ; \mathrm{p}<0.01$ ). After this initial evaluation, only the subjective impression at subsequent examinations was taken into account.

Categorical variables were represented as absolute numbers and percentages, while continuous variables were expressed as medians (interquartile deviations [IQD]). Comparisons were made using bivariate analysis between the group of women who complained of hair loss and the non-complainer group using the chi-square test, Fisher's exact test, William's test or the Mann-Whitney U test. 
Correlations were determined using Spearman's rank correlation coefficient and the normal distribution of data was determined using the Shapiro-Wilk test. In the multivariate analysis, abnormal distributions were ranked.

The variables with a two-tailed p-value $<0.30$ in the bivariate analyses were included in the conditional multiple logistic regression. Next, the model was reduced using a backward stepwise algorithm, maintaining the variables with two-tailed p-values < 0.30 in the final model.

The minimum sample size was calculated at 156 individuals for a multiple logistic regression with a power of $80 \%$ and alpha level of 0.05 to detect an anticipated effect size of 0.15 and include up to 20 covariates.

The coefficients of the categorical and logistic associations were represented by the odds ratios (OR) and their respective $95 \%$ confidence intervals (95\%CI). Two-tailed p-values $<0.05$ were considered statistically significant.

\section{RESULTS}

The study interviewed 157 women with a median (IQD) age of 51 (20) years. The five most common dermatoses were melasma $(11 \%)$, solar lentigo or solar melanosis $(11 \%)$, actinic keratosis $(10 \%)$, acne (6\%) and onychomycosis (6\%).

Following specific questioning, 54\% of the women reported having a problem with hair loss. The way in which the problem was perceived was, in decreasing order: while combing the hair (41\%), while in the bath (40\%), from the amount of hair found on the floor (27\%) or on the pillow (20\%), hair thinning (12\%) and from observations made by others (6\%). There was a significant association between the physician's perception and the patient's perception of the presence of hair thinning $(\mathrm{OR}=22.83$; 95\%CI: $5.44-95.77 ; \mathrm{p}<0.01$; Fisher's exact test).

The length of the hair correlated significantly with age, shorter hair being associated with older women (Spearman's rho $=-0.48 ; \mathrm{p}<0.01$ ).

Overall, $55 \%$ of the women interviewed did not associate the treatment of hair loss with the dermatologist and there was no statistically significant difference in age between those who were aware of the scope of this specialist and those who were not (median [IQD] age 48 [21] years versus 52.5 [22] years; $\mathrm{p}=0.18$; Mann-Whitney).

The median (IQD) number of hairs obtained in the hair pull test was 1 (2) (range 0-12) and was correlated with hair length (Spearman's rho $=0.26$; $\mathrm{p}<0.01$ ).

Seventeen patients (11\%) had chronic diseases related to hair loss, the most common being hypothy- roidism (14 women). These 17 patients were the ones in whom the most hairs were obtained in the hair pull test (median [IQD] number of hairs 2 [1] versus 1 [2], $\mathrm{p}=0.02$; Mann-Whitney test).

At least $22 \%$ of the patients were in regular use of medication associated with hair loss, the most common being beta-blockers and antidepressants.

Of the women interviewed, $29 \%$ reported at least two key symptoms of depression and $20 \%$ had symptoms compatible with dysthymia.

The patients who complained of hair loss reported that the problem had been present for a median (IQD) duration of 12 (30) months, with a correlation between the patient's age at the time of the interview and the duration of hair loss (Spearman's rho $=0.26 ; \mathrm{p}=0.02$ ).

In the bivariate comparisons between the two groups, the women complaining of hair loss were more likely to have a family history of alopecia, longer hair, seborrheic dermatitis, and more hairs removed in the hair pull test. Additionally, the complainers were more likely to have symptoms of depression and personal relationship problems compared to the women who had not complained of hair loss (Table 1).

No differences in median age were found between the group of women complaining of hair loss and the group of non-complainers. However, when sub-groups of age were analyzed, women of 20-39 years of age were more likely to complain of hair loss than those of $40-59$ years of age $(\mathrm{OR}=2.55,95 \% \mathrm{CI}$ : $1.11-5.82 ; \mathrm{p}=0.02$; chi-square test).

In the multivariate analysis, there were statistically significant differences between the group of women that had complained of hair loss and the group that had not with respect to age, knowledge regarding the scope of the dermatologist, family history of alopecia, the presence of hair thinning and the presence of symptoms of depression (Table 2).

The association between hair loss and the presence of two or more key symptoms of depression appeared to be restricted to the younger half of the sample (Table 3).

\section{DISCUSSION}

In this culture, hair plays a very significant role in gender identification and often acts as a fashion item, a reference of beauty and style. Long, voluminous hair is thus representative of health and youthfulness. Based on this, we have found that a perception of hair loss may lead to feelings of loss of health and of senility, generating significant psychological stress that, in turn, may be associated with causing hair loss, thereby increasing the amount of telogen hair. ${ }^{7}$

When questioned, more than half the women interviewed reported problems with hair loss, which 
TABLE 1: Bivariate comparison of the characteristics evaluated according to their association with the complaint of hair loss $(n=157)$

\begin{tabular}{|c|c|c|c|c|c|}
\hline Variable & Total & Complaint & $\begin{array}{l}\text { No } \\
\text { complaint }\end{array}$ & OR $(95 \% \mathrm{CI})$ & p-value \\
\hline Age* & $51[20]$ & $47[20]$ & $52.5[18]$ & - & 0.11 \\
\hline Phototype** & - & - & - & - & 0.35 \\
\hline Aware of the scope of the dermatologist*** & $71[45]$ & $34[40]$ & $37[51]$ & $0.63(0.33-1.19)$ & 0.15 \\
\hline Family history of alopecia** & $66[42]$ & $44[52]$ & $22[31]$ & $2.44(1.26-4.71)$ & $<0.01$ \\
\hline Actual hair type** & $-\quad 1$ & -1 & 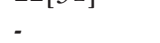 & - & 0.89 \\
\hline Current hair type $* *$ & - & - & - & - & 0.49 \\
\hline Actual hair color is dark** & $108[69]$ & $58[68]$ & $50[69]$ & $0.95(0.48-1.86)$ & 0.87 \\
\hline Current hair color is dark** & $95[61]$ & $53[62]$ & $42[58]$ & $1.18(0.62-2.25)$ & 0.61 \\
\hline Number of shampoos per week* & $3[1]$ & $3[1]$ & $3[1]$ & - & 0.22 \\
\hline Number of times hair is combed per day* & $2[2]$ & $2[2]$ & $2[2]$ & - & 0.82 \\
\hline Length* & $27[25]$ & $30[20]$ & $22[26]$ & - & 0.01 \\
\hline Regular coloring** & $54[34]$ & $27[32]$ & $27[38]$ & $0.78(0.40-1.50)$ & 0.45 \\
\hline Number of hairs obtained in the hair pull test* & $1[2]$ & $1[2]$ & $1[1]$ & - & 0.02 \\
\hline Current acne** & $20[13]$ & $15[18]$ & $5[7]$ & $2.87(0.99-8.34)$ & 0.06 \\
\hline Seborrhea of the scalp** & $45[29]$ & $32[38]$ & $13[18]$ & $2.74(1.30-5.76)$ & $<0.01$ \\
\hline Hirsutism** & $4[3]$ & $2[2]$ & $2[3]$ & $0.84(0.12-6.14)$ & 0.99 \\
\hline Two or more key symptoms of depression** & $45[29]$ & $32[38]$ & $13[18]$ & $2.74(1.30-5.77)$ & $<0.01$ \\
\hline Problems with personal relationships** & $23[15]$ & $17[20]$ & $6[8]$ & $2.75(1.02-7.4)$ & 0.04 \\
\hline Hair thinning on the vertex region of the scalp** & $15[10]$ & $11[13]$ & $4[6]$ & $2.56(0.78-8.43)$ & 0.17 \\
\hline Presence of pathologies associated with hair loss ** & $17[11]$ & $11[13]$ & $6[8]$ & $1.64(0.57-4.67)$ & 0.44 \\
\hline Use of drugs associated with hair loss** & $34[22]$ & $15[18]$ & $19[26]$ & $0.60(0.28-1.29)$ & 0.19 \\
\hline Use of antidepressants** & $16[10]$ & $7[8]$ & $9[13]$ & $0.63(0.22-1.78)$ & 0.43 \\
\hline
\end{tabular}

* Data shown as medians and interquartile deviations and compared using the Mann-Whitney test.

** Categorical data shown as absolute numbers and percentages. Data compared using the chi-square test or Fisher's exact test.

was most often noticed during their regular hair-care routine such as when washing or combing their hair. Most of the patients were undergoing treatment for mild skin disorders, some of which were almost entirely cosmetic; therefore, there is a possibility that this population may be more sensitive to hair-related problems than patients with more severe dermatological disorders. It is important to emphasize that cosmetic problems are currently routine in dermatology clinics and it is important to recognize the profile of these patients. ${ }^{8}$

Surprisingly, the majority of these patients were unaware that dermatologists treat hair loss and this lack of information does not appear to be associated specifically with older patients. This finding indicates that, at least in the case of patients in the public healthcare network, information should be provided on the types of treatment available within the scope of dermatology.'

The presence of clinical conditions or the use of drugs that could cause hair loss was rare in the patients evaluated in this study. Nonetheless, more hairs were obtained in the hair pull test in patients with diseases associated with hair loss, the most common being hypothyroidism. It should be emphasized that possible confounding factors related to this fin- ding, such as whether these conditions were being effectively treated at the time and the concomitant use of other medications that could adversely affect the hair, were not evaluated.

In the bivariate analyses, a significant association was found between a complaint of hair loss and the length of the hair or the number of hairs obtained in the hair pull test. However, the multivariate analysis failed to confirm these findings. This was probably due to the significant correlation between these variables, as well as the significant correlation between hair length and age, since only age was found to be independently associated with hair loss in the final model. These data show that the number of hairs obtained in the hair pull test does not represent a good independent predictor of the perception of hair loss by the patient. On the other hand, the perception of hair loss was independently associated with the presence of hair thinning.

The above observations indicate that predefining an absolute normal limit for the hair pull test may be difficult and that the length of the hair being tested should be taken into consideration.

The multivariate analysis suggested that in the age group evaluated, younger women are more likely to complain of hair loss. Various factors may be asso- 
TABLE 2: Final multiple logistic regression model according to the backward stepwise algorithm of the variables associated with hair loss $(\mathrm{n}=157)^{*}$

\begin{tabular}{lllll}
\hline Variable & Odds ratio & 95\% CI & & p-value \\
\hline Aware of the scope of the dermatologist & 0.44 & 0.20 & 0.95 & 0.04 \\
Family history of alopecia & 2.86 & 1.32 & 6.19 & $<0.01$ \\
Seborrheic dermatitis of the scalp & 2.34 & 0.96 & 5.68 & 0.06 \\
Problems with personal relationships & 2.59 & 0.82 & 8.20 & 0.11 \\
Thinning of the hair on the vertex region of the scalp & 7.15 & 1.64 & 31.18 & $<0.01$ \\
Two or more key symptoms of depression & 2.79 & 1.18 & 6.61 & 0.02 \\
Use of drugs that could potentially cause hair loss & 0.45 & 0.18 & 1.13 & 0.09 \\
Number of shampoos per week** & 0.99 & 0.98 & 1.00 & 0.05 \\
Number of hairs obtained in the hair pull test** & 1.01 & 0.99 & 1.01 & 0.28 \\
Age** & 0.99 & 0.98 & 0.99 & 0.03 \\
Constant & 1.92 & 0.00 & 0.00 & 0.42 \\
\hline
\end{tabular}

"Dependent variable: Complaint of hair loss; p-value (of the model) $<0.001$;

Correct classification $=71.3 \%$; R2 Nagelkerke $=0.32$.

${ }^{* *}$ Ranks.

ciated with this finding, including cultural and psychological aspects typical of different generations or of different age groups of women. ${ }^{10}$

Since a considerable proportion of the patients would be in the menopausal transition, principally those in the younger half of the sample, the effect of this phase of hormonal changes on the association between a complaint of hair loss and younger age, cannot be excluded. However, these data indicate that the younger adults were more likely to complain of hair loss than those in the age group associated with the perimenopause, suggesting that factors related to this complaint may be more significant at the beginning of adulthood in these patients.

The data show a significant association between symptoms of depression and a complaint of hair loss, principally with respect to the patients in the third and fourth decades of life.

In general, there is a greater prevalence of mood disorders in outpatients compared to the healt-

TABLE 3: Association between a complaint of hair loss and the presence of two or more key symptoms of depression

\begin{tabular}{lll}
\hline Analysis & $\begin{array}{l}\text { Age }<51 \text { years } \\
(\mathbf{n}=76) \\
\text { OR }[95 \% \mathbf{C I}]\end{array}$ & $\begin{array}{l}\text { Age } \geq 51 \text { years } \\
\mathbf{( n = 8 1 )} \\
\text { OR }[95 \% \mathbf{C I}]\end{array}$ \\
\hline Crude & $5.00[1.50-16.66]$ & $1.63[0.60-4.44]$ \\
Adjusted* & $4.48[1.07-18.82]$ & $1.92[0.54-6.85]$ \\
\hline
\end{tabular}

* Adjusted for age, family history, awareness of the scope of the dermatologist, use of drugs associated with hair loss, seborreheic dermatitis of the scalp, problems with personal relationships, number of hairs obtained in the hair pull test and the number of shampoos per week. hy population; nonetheless, few studies have evaluated the association between these symptoms and hair loss. ${ }^{11}$ Since $38 \%$ of the patients who reported hair loss had at least two of the three key symptoms of depression, it is probable than many of these patients would have benefitted from psychological evaluation, which does not generally form part of the typical clinical management of dermatology patients.

There are numerous factors related to hair loss and to the perception of hair loss that may not be completely coincidental. The apparently higher frequency of this complaint among young adults together with the greater association of the complaint with symptoms of depression and with relationship problems suggest a close association between this perception ${ }_{9}$ and the psychological well being of these women.

The above-mentioned association was not found among the patients over 50 years of age, possibly because there are more comorbidities and conditions that trigger symptoms of depression in this age group, as well as a proven increase in the prevalence of depression and organic cerebral syndrome, which may present in a similar form in the elderly population in general. ${ }^{12}$

The present study does not permit causal relationships to be established between the perception of hair loss and the presence of symptoms of depression. Furthermore, the presence of uninvestigated underlying conditions that could be acting on a possible hair loss and on the patient's mood cannot be discarded. However, they were not the objectives of the present study.

Nonetheless, mood changes cannot be eliminated as causes of hair loss. Some molecular studies and studies in animal models have shown that psychologi- 
cal stress may act on the hair follicle cycle, accelerating the transition into the telogen phase and provoking miniaturization of the follicle. Suppression of the hormones related to stress may reverse these effects. ${ }^{13}$

\section{CONCLUSIONS}

In the region in which this study was conducted, hair loss was present in a large percentage of the adult female patients attending a public dermatology clinic, even when this complaint was not the reason for the patient to seek consultation at the clinic.
The most common ways in which the problem was perceived by the patient were when combing the hair or when bathing. Half the patients did not associate the treatment of hair loss with dermatologists, suggesting a need to inform the public on the scope within this specialty.

Finally, the perception of hair loss was found to be independently associated with a greater prevalence of symptoms of depression, principally in adult women up to the fifth decade of life. However, further studies with larger sample sizes and specific designs should be conducted to define the association between these observations.

\section{REFERENCES}

1. Alfonso M, Richter-Appelt H, Tosti A, Viera MS, García M. The psychosocial impact of hair loss among men: a multinational European study. Curr Med Res Opin. 2005;21:1829-36.

2. Grimalt R. Psychological aspects of hair disease. J Cosmet Dermatol. 2005;4:142-7.

3. Cash TF, Price VH, Savin RC. Psychological effects of androgenetic alopecia on women: comparisons with balding men and with female control subjects. J Am Acad Dermatol. 1993;29:568-75.

4. Girman CJ, Hartmaier S, Roberts J, Bergfeld W, Waldstreicher J. Patient-perceived importance of negative effects of androgenetic alopecia in women. J Womens Health Gend Based Med. 1999;8:1091-5.

5. Cash TF. The psychosocial consequences of androgenetic alopecia: a review of the research literature. Br J Dermatol. 1999;141:398-405.

6. Fleck MP, Berlim MT, Lafer B, Sougey EB, Del Porto JA, Brasil MA, et al. Revisão das diretrizes da Associação Médica Brasileira para o tratamento da depressão (Versão integral). Rev Bras Psiquiatr. 2009;31(Supl 1):S7-17.

7. Botchkarev VA. Stress and the hair follicle: exploring the connections. Am J Pathol. 2003;162:709-12.

8. Sociedade Brasileira de Dermatologia. Perfil nosológico das consultas dermatológicas no Brasil. An Bras Dermatol. 2006;81:549-58.

9. Williamson D, Gonzalez M, Finlay AY. The effect of hair loss on quality of life. J Eur Acad Dermatol Venereol. 2001;15:137-9.

10. Hadshiew IM, Foitzik K, Arck PC, Paus R. Burden of hair loss: stress and the underestimated psychosocial impact of telogen effluvium and androgenetic alopecia. $\mathrm{J}$ Invest Dermatol. 2004;123:455-7.

11. Veras $A B$, Rassi $A$, Valença AM, Nardi AE. Prevalência de transtornos depressivos e ansiosos em uma amostra ambulatorial brasileira de mulheres na menopausa. Rev Psiquiatr RS. 2006;28:130-4

12. Gazalle FK, Hallal PC, Lima MS. Depressão na população idosa: os médicos estão investigando? Rev Bras Psiquiatr. 2004;26:145-9.

13. Wang L, Million M, Rivier J, Rivier C, Craft N, Stenzel-Poore MP, Taché Y. CRF Receptor Antagonist Astressin-B Reverses and Prevents Alopecia in CRF OverExpressing Mice. PLoS One. 2011;6:e16377.

How to cite this article: Schmitt JV, Ribeiro CF, Souza FHM, Siqueira EBD, Bebber FRL. Hair loss perception and symptoms of depression in female outpatients attending a general dermatology clinic. An Bras Dermatol. 2012;87(3):412-7. 